\title{
High-Utilisation Nanoplatinum Catalyst (Pt@cPIM) Obtained via Vacuum Carbonisation in a Molecularly Rigid Polymer of Intrinsic Microporosity
}

\author{
Yuanyang Rong ${ }^{1} \cdot$ Daping $\mathrm{He}^{1} \cdot$ Richard Malpass-Evans $^{2} \cdot$ Mariolino Carta $^{2}$. \\ Neil B. McKeown ${ }^{2}$. Murilo F. Gromboni ${ }^{3}$ - Lucia H. Mascaro ${ }^{3}$ - Geoffrey W. Nelson ${ }^{4}$. \\ John S. Foord ${ }^{5} \cdot$ Philip Holdway $^{6} \cdot$ Sara E. C. Dale ${ }^{7} \cdot$ Simon Bending $^{7} \cdot$ Frank Marken $^{1}$
}

Published online: 12 December 2016

(C) The Author(s) 2016. This article is published with open access at Springerlink.com

\begin{abstract}
Polymers of intrinsic microporosity (PIM or here PIM-EA-TB) offer a highly rigid host environment into which hexachloroplatinate(IV) anions are readily adsorbed and vacuum carbonised (at $500^{\circ} \mathrm{C}$ ) to form active embedded platinum nanoparticles. This process is characterised by electron and optical microscopy, atomic force microscopy (AFM), X-ray photoelectron spectroscopy (XPS) and electrochemical methods, which reveal that the PIM microporosity facilitates the assembly of nanoparticles of typically 1.0 to $2.5-\mathrm{nm}$ diameter. It is demonstrated that the resulting carbonised "Pt@cPIM" from drop-cast films of ca. 550-nm average thickness, when prepared on tin-doped indium oxide (ITO), contain not only fully encapsulated but also fully active platinum nanoparticles in an electrically conducting heterocarbon host. Alternatively, for thinner films (50-250 nm)
\end{abstract}

Frank Marken

f.marken@bath.ac.uk

1 Department of Chemistry, University of Bath, Claverton Down, Bath BA2 7AY, UK

2 EastChem School of Chemistry, University of Edinburgh, David Brewster Road, Edinburgh EH9 3FJ, UK

3 Department of Chemistry, Federal University of São Carlos, Rod. Washigton Luiz, km235, CEP, São Carlos, SP 13565-905, Brazil

4 Department of Materials, Imperial College London, Royal School of Mines, Exhibition Road, London SW7 2AZ, UK

5 Chemistry Research Laboratories, Oxford University, South Parks Road, Oxford OX1 3TA, UK

6 Department of Materials, Oxford University, Begbroke Science Park, Begbroke Hill, Oxford OX5 1PF, UK

7 Department of Physics, University of Bath, Claverton Down, Bath BA2 7AY, UK prepared by spin coating, the particles become more exposed due to additional loss of the carbon host. In contrast to catalyst materials prepared by vacuum-thermolysed hexachloroplatinate(IV) precursor, the platinum nanoparticles within Pt@cPIM retain high surface area, electrochemical activity and high catalyst efficiency due to the molecular rigidity of the host. Data are presented for oxygen reduction, methanol oxidation and glucose oxidation, and in all cases, the high catalyst surface area is linked to excellent catalyst utilisation. Robust transparent platinum-coated electrodes are obtained with reactivity equivalent to bare platinum but with only $1 \mu \mathrm{g} \mathrm{Pt} \mathrm{cm}{ }^{-2}$ (i.e. $~ 100 \%$ active Pt nanoparticle surface is maintained in the carbonised microporous host).

Keywords Fuel cell $\cdot$ Noble metal $\cdot$ Nanocatalyst $\cdot$ One-step synthesis $\cdot$ Encapsulation $\cdot$ Voltammetry

\section{Introduction}

The preparation and formulation of catalysts for applications in fuel cells [1] and in sensors [2] remain a highly active research topic. For example, the development of new types of porous substrate materials [3] offer catalysts with (i) better levels of performance [4, 5], (ii) improved access into a wide range of reproducible and highly efficient catalyst composites [6] and/or (iii) access to more sustainable catalyst systems [7]. Many new inorganic [8] or carbon-based catalyst composite materials $[9,10]$ are under development, and in particular, synthetic methods based on the carbonisation of precursors to yield carbon-embedded catalysts $[11,12]$ have proved beneficial. Novel and highly efficient types of carbon-embedded platinum catalysts have been obtained via carbonisation [13]. However, directly embedding active nanoplatinum catalysts 
without loss of activity during carbonisation in a one-step procedure is uncommon and desirable.

Platinum nanoparticles are the basis for the overwhelming majority of technical catalyst systems due to the durability of platinum and due to the special place platinum takes with respect to interfacial adsorption of reaction intermediates [14]. Platinum nanoparticles are employed not only in PEM fuel cells [15], in methanol [16] and in glucose [17] driven fuel cells but also in many dye-sensitised solar cells [18] and in electrolysers for energy conversion [19]. The most active size range for platinum has been reported to be $2-6 \mathrm{~nm}$ (based on mass activity) [20]. However, the catalyst durability and corrosion characteristics are also important [21]. We have recently demonstrated that a new class of polymers with intrinsic microporosity (PIMs) can be employed to stabilise Pt nanoparticle performance for both anode and cathode activity [22, 23].

Platinum nanoparticles provide very effective catalysts but suffer from high cost of the non-sustainable noble metal catalyst. Therefore, intense research efforts are directed towards either replacing platinum with cheaper and more sustainable metals (e.g. based on alloys of $\mathrm{Fe}, \mathrm{Co}$, Ni, etc. [24]) or improving utilisation. The latter involves maximising the surface area and reactivity of platinum, for example, by embedding nanoparticles into porous hosts or substrates [25]. Porous polymer materials are emerging as promising substrates (or precursors for porous substrates) for the immobilisation and growth of platinum nanocatalysts [26]. Highly porous polymer structures that can retain microporosity during carbonisation are particularly interesting. For PIM materials, it has been suggested that carbonisation occurs via crosslinking and without breaking of the rigid polymer backbone strands [27].

Polymers of intrinsic microporosity (or PIMs [28]) exhibit micropore diameter of typically $0.5-2.0 \mathrm{~nm}$ and $\mathrm{N}_{2}$ adsorption surface area values up to $1000 \mathrm{~m}^{2} \mathrm{~g}^{-1}$ [29]. They were originally developed for gas storage [30] and separation [31] but recently have also proven utility for electrochemical processes such as electrocatalysis [32], ionic devices [33] or electroanalysis [34]. Most work in PIM electrochemistry to date has been carried out with PIM-EA-TB (prepared from a diaminoethanoanthracene "EA" monomer polymerised via a Tröger base "TB" coupling; see structure in Fig. 1). This polymer with highly rigid molecular structure exhibits $\mathrm{N}_{2}$ adsorption surface area of $1027 \mathrm{~m}^{2} \mathrm{~g}^{-1}$ and is employed here with molecular weight of $70 \mathrm{kDa}$ [33].

We have demonstrated previously that relatively gentle vacuum carbonisation of PIM-EA-TB at $500{ }^{\circ} \mathrm{C}$ causes conversion of the microporous starting material into a microporous conducting hetero-carbon [27]. Although the electrical conductivity of the new carbon material was limited, thin films deposited onto tin-doped indium oxide (ITO) substrates were clearly capacitive and suitable for application as high surface area carbon film electrodes. A key feature in the conversion of PIM-EA-TB to the carbonised form (cPIM) is the retention of structural porosity/integrity. There were no changes in cumulative pore volume and no apparent changes in morphology upon vacuum carbonisation [27]. Therefore, this hetero-carbon formation may offer ideal conditions for the coformation/embedding of nanocatalysts with the following advantages: (a) The rigid PIM-EA-TB does not block/affect the catalytically active Pt particle surface, and (b) after carbonisation, porosity and connectivity are maintained to allow electrical contact and sufficient access for reactants to the active catalyst surface.

Here, we add a well-defined amount of platinum precursor $\left(\mathrm{PtCl}_{6}{ }^{2-}\right)$ by absorption into the porous protonated form of PIM-EA-TB, and during subsequent vacuum carbonisation, nanoparticulate platinum is formed in situ and without encapsulation or blocking of the active catalyst surface (Fig. 1). The microporous hetero-carbon host surrounding the platinum nanocatalyst ensures good electrical connection and therefore excellent catalyst utilisation.

It is shown that PIM-EA-TB as a precursor host material can be employed to generate/maintain platinum nanoparticle size (at typically $1.0-2.5 \mathrm{~nm}$ ) and to improve nanocatalyst performance by building up thicker layers of catalyst (with additive performance). Catalysts are prepared in a simple one-step vacuum carbonisation process in which the PIMEA-TB polymer is converted into an electrically conducting host (of similar porosity) containing the platinum nanoparticle catalyst in a way that it is accessible to the solution phase. In contrast to solution casting, spin coating produces thinner films which, when carbonised, give highly effective platinum catalyst layers on transparent ITO electrode surfaces.

\section{Experimental}

\section{Chemical Reagents}

Dipotassium platinum(IV)hexachloride, D-(+)-glucose, phosphoric acid (85\%), sodium hydroxide, perchloric acid (96\%), sodium chloride and hydrochloric acid (30\%) were purchased in analytical grade from Aldrich or Fisher Scientific and used without further purification. PIM-EA-TB was prepared following the literature procedure [35]. All solutions were prepared using deionised water (resistivity $18 \mathrm{M} \Omega \mathrm{cm}$ at $22{ }^{\circ} \mathrm{C}$ ) from a Thermo Scientific water purification system.

\section{Instrumentation}

Heating was performed in a TSH12 tube furnace (Elite Thermal System Ltd.). Pt nanoparticle materials were characterised by transmission electron microscopy (TEM) on a Jeol 1200EXII TEM system (with EDS 
Fig. 1 Schematic representation of the formation of a film of PIMEA-TB $(i)$, absorption of $\mathrm{PtCl}_{6}{ }^{2-}$ into the film (ii) and vacuum carbonisation at $500{ }^{\circ} \mathrm{C}$ to give highly porous hetero-carbon materials with/without nanoplatinum catalyst (iii)

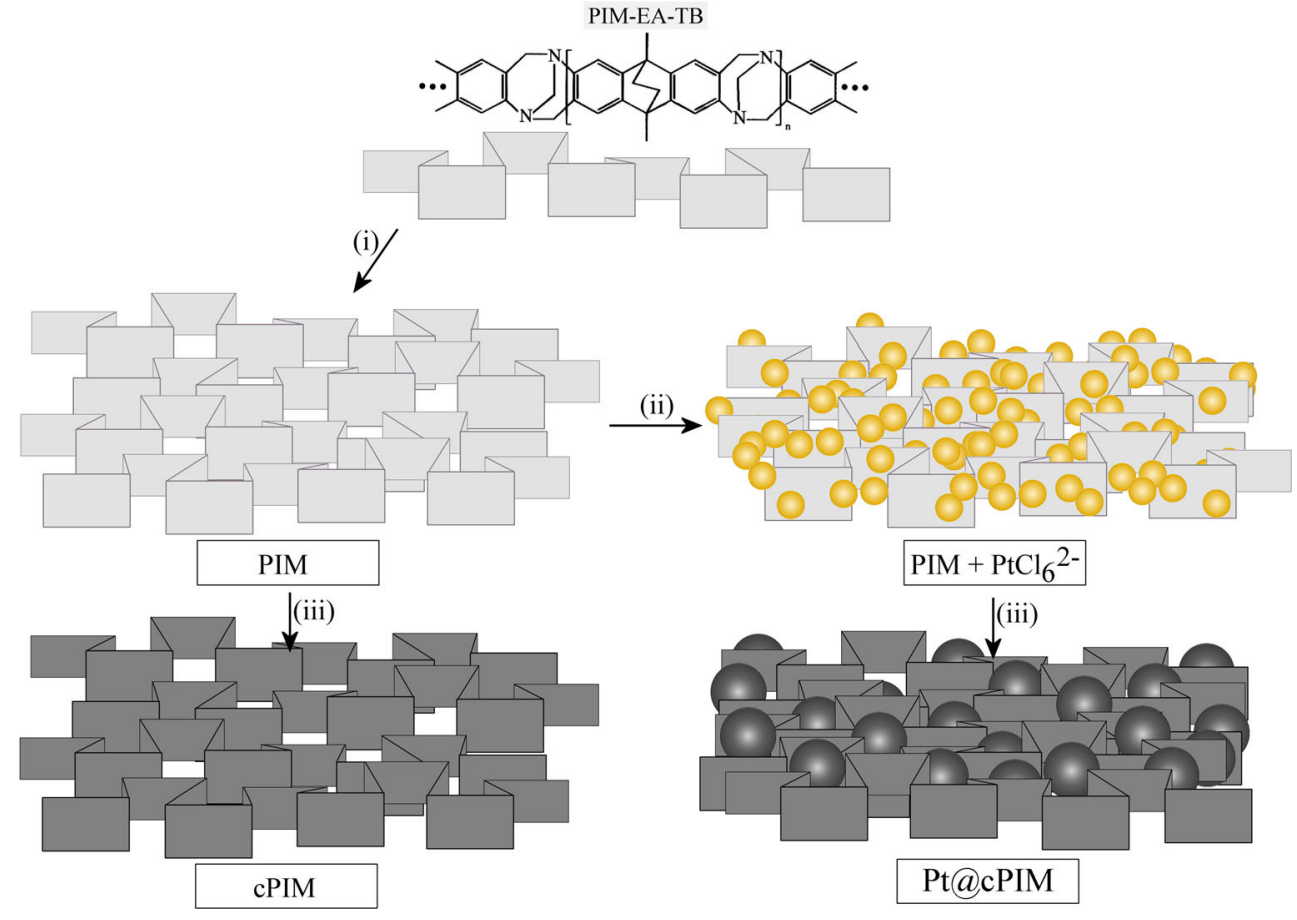

and STEM). All electrochemical measurements were performed using an Ivium Compactstat potentiostat (The Netherlands) with platinum wire counter electrode and $\mathrm{KCl}$-saturated calomel reference electrode (SCE, Radiometer REF401). The working electrode was prepared from ITO-coated glass (tin-doped indium oxide films sputter-coated onto glass, active area $15 \times 15 \mathrm{~mm}$, resistivity ca. $15 \Omega$ per square) obtained from Image Optics Components Ltd. (Basildon, Essex, UK). X-ray photoelectron spectroscopy (XPS) data were obtained on a Kratos Axis Ultra DLD system using a fixed anode monochromatic $\mathrm{Al} \mathrm{K} \alpha \mathrm{X}$-ray source operating at $120 \mathrm{~W}$.

\section{Preparation of Thick Film Pt@cPIM on Tin-Doped Indium Oxide}

An aqueous platinum precursor solution was prepared by dissolving $10 \mathrm{mM} \mathrm{K}_{2} \mathrm{PtCl}_{6}$ in $0.5 \mathrm{M} \mathrm{HCl}$ (this solution was unstable as indicated by a slow colour change from yellow to orange and therefore stored in the dark at $4{ }^{\circ} \mathrm{C}$ ). A ITO electrode was coated with $60 \mu \mathrm{L}$ ( $1 \mathrm{mg} \mathrm{mL}^{-1}$ in chloroform) PIM-EA-TB in a drop-cast process giving approximately in average 550-nm-thick deposits. Next, the ITO with PIM-EATB layer was dipped into the platinum precursor solution for $5 \mathrm{~min}$ (to allow sufficient time for ion exchange), then rinsed with water and dried under ambient conditions. The colour changed from clear to yellow. After the $\mathrm{PtCl}_{6}{ }^{2-}$ impregnation step, the ITO electrode was subjected to vacuum carbonisation under oil pump vacuum (ca. $0.1 \mathrm{mTorr}$ ) in a quartz tube to fit the tube furnace at $500{ }^{\circ} \mathrm{C}$ for $3 \mathrm{~h}$ to obtain cPIM-Pt with embedded platinum nanoparticles. Elemental analysis (Butterworth Analytical Laboratories, London) was performed for two samples: (a) for PIM-EA-TB treated with $\mathrm{Pt}(\mathrm{IV}) \mathrm{Cl}_{6}{ }^{2-}$ : Pt 6.8\%, C 55.5\%, $\mathrm{H} \mathrm{5.2 \%} \mathrm{and} \mathrm{N} 6.2 \%$ and (b) for cPIM-Pt: Pt 10.2\%, C 72.4\%, H $2.1 \%$ and $\mathrm{N} 5.7 \%$. Residual mass is likely to be associated with inorganic components such as $\mathrm{KCl}$. Note that the ratio of platinum atoms to nitrogen atoms in PIM-EA-TB treated with $\mathrm{Pt}(\mathrm{IV}) \mathrm{Cl}_{6}{ }^{2-}$ is 0.08 (or $8 \%$ ), which suggests that only partial loading of the polymer was achieved.

\section{Preparation of Thin Film Pt@ cPIM on Tin-Doped Indium Oxide}

PIM-EA-TB was dissolved in chloroform to prepare solutions with four different concentrations $(0.25,0.5,1$ and $2 \mathrm{wt} \%)$. Spin coating of these solutions (WS-650Mz-23NPP, Laurell Technologies) using a rotation rate of $1500 \mathrm{rpm}$ for $1 \mathrm{~min}$ and ITO substrates of $15 \mathrm{~mm} \times 15 \mathrm{~mm}$ area resulted in different thicknesses of PIM-EA-TB (vide infra). Next, the coated electrode was immersed into the platinum precursor solution (as before) for $5 \mathrm{~min}$, then rinsed with water and dried under ambient conditions. Then, the ITO electrode was transferred to vacuum carbonisation under oil pump vacuum (Edwards, ca. 0.1 mTorr) in a quartz tube at $500{ }^{\circ} \mathrm{C}$ for $3 \mathrm{~h}$ to give Pt@cPIM thin films with platinum nanoparticles embedded. 


\section{Results and Discussion}

\section{Formation and Characterisation of Thick Film Pt@cPIM}

Drop casting was employed with $60 \mu \mathrm{L}$ of a PIM-EA-TB solution in chloroform $\left(1 \mathrm{mg} \mathrm{mL}^{-1}\right)$ applied to an ITO electrode. With the measured film density of $1.1 \mathrm{~g} \mathrm{~cm}^{-3}$ for PIM-EA-TB [36], this allows an average film thickness to be estimated as $550 \mathrm{~nm}$. With platinum bound into the film (see elemental analysis results in the "Experimental" section), a coverage of about $6 \mu \mathrm{g} \mathrm{Pt} \mathrm{cm}{ }^{-2}$ is anticipated. Under $\mathrm{PtCl}_{6}{ }^{2-}$ absorption conditions employed here, only approximately $8 \%$ of the nitrogen atoms in the polymer are associated with a platinum. The vacuum carbonisation process when applied to a film of PIM-EA-TB on an ITO substrate is known to produce a nitrogen-containing hetero-carbon with significant electrical conductivity, characteristic Raman signature for a graphitic structure, retained cumulative pore volume/morphology and black coloration of carbon [27]. The $\mathrm{N}_{2}$ adsorption data for PIM-EA-TB suggest a surface area of $1027 \mathrm{~m}^{2} \mathrm{~g}^{-1}$ before carbonisation [33] and $242 \mathrm{~m}^{2} \mathrm{~g}^{-1}$ after carbonisation [27].
Here, PIM-EA-TB only is vacuum carbonised to give cPIM and with absorbed $\mathrm{PtCl}_{6}{ }^{2-}$ in the porous structure to give Pt@cPIM. Figure 2 shows TEM evidence for the presence of cPIM carbon material and for the embedded Pt nanoparticles in Pt@cPIM (contrast Fig. 2a, b). Higher magnification (Fig. 2c, d) allows individual particles (black or grey) to be analysed, and the average particle size to be estimated is typically 1.0 $2.5 \mathrm{~nm}$. This value is similar to the micropore size for the PIMEA-TB polymer starting material (from $\mathrm{N}_{2}$ gas adsorption isotherm data [33]). Electron diffraction data (Fig. 2e, f) clearly confirm that the carbonisation process leads to inclusion of platinum nanoparticles. The diffraction rings are consistent with $\operatorname{Pt}(331), \operatorname{Pt}(222), \operatorname{Pt}(311), \operatorname{Pt}(220), \operatorname{Pt}(200)$ and $\operatorname{Pt}(111)$ (compare JCPDS 4-0802 structure information [37]).

\section{Formation and Characterisation of Thin Film Pt@cPIM}

When employing spin coating instead of drop casting, betterdefined coatings of PIM-EA-TB can be produced. By changing the wt\% of PIM-EA-TB in chloroform and keeping the spin coating conditions constant (see "Experimental" section), film thickness can be varied from about 50 to $250 \mathrm{~nm}$ (based
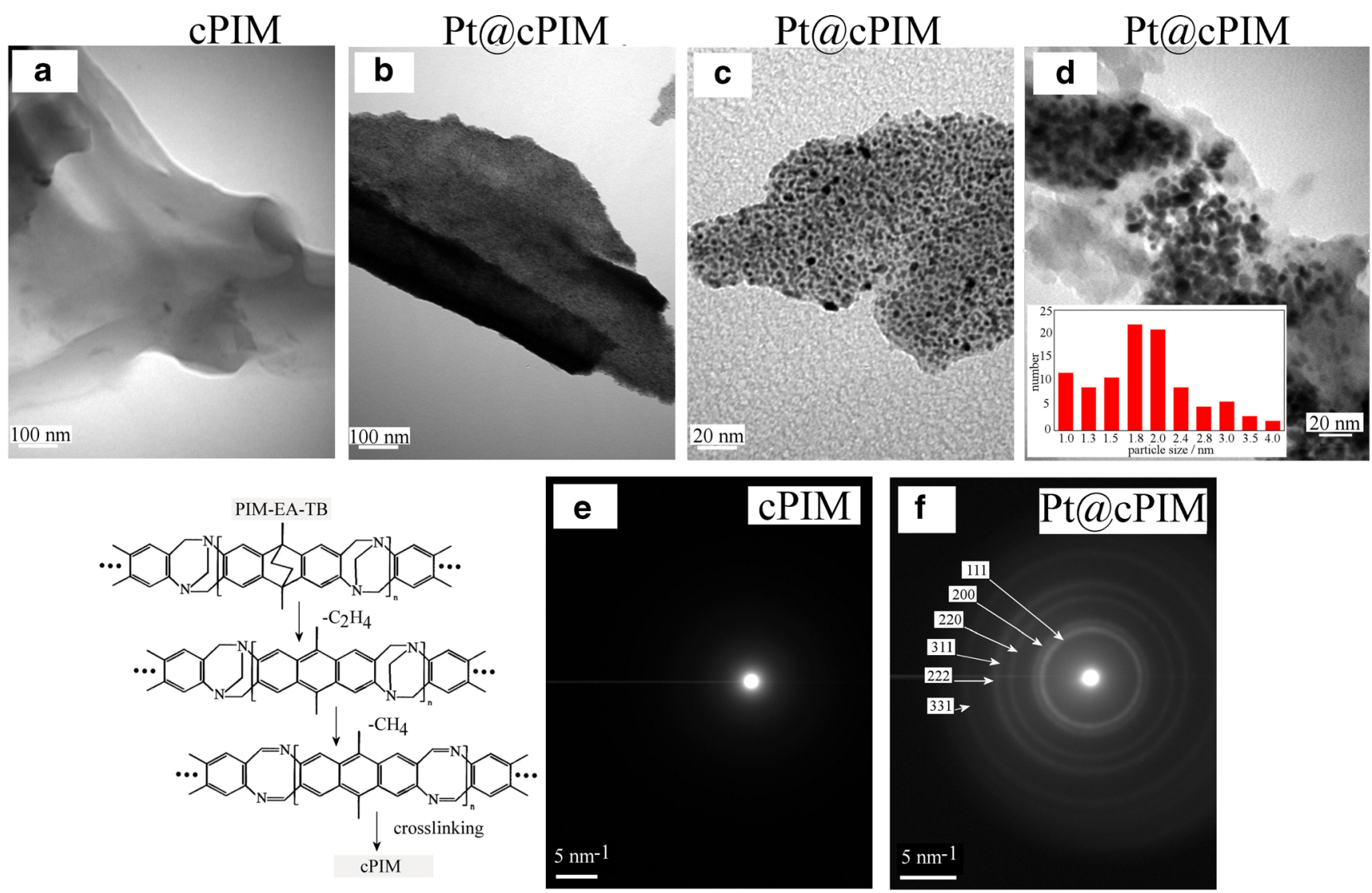

Fig. 2 Transmission electron micrographs for a thick cPIM, b thick Pt@cPIM, $\mathbf{c}$ thick Pt@cPIM and $\mathbf{d}$ thin film Pt@cPIM with particle size analysis. Also shown is a schematic reaction pathway for carbonisation and diffraction pattern for e cPIM and $\mathbf{f}$ Pt@cPIM 
on atomic force microscopy (AFM) cross-sectional data, see Fig. 3). These films are more uniform compared to deposits formed by drop casting. AFM images of bare ITO and cPIMcoated ITO are shown in Fig. 3a, b consistent with a uniform coating. Perhaps surprisingly, when $\mathrm{PtCl}_{6}{ }^{2-}$ is absorbed into the PIM deposit prior to vacuum carbonisation, the morphology is affected and only thinner deposits seem to remain (see the more apparent substrate grain boundaries in Fig. 3c). This observation is confirmed by SEM imaging.

Figure 4 shows both cross-sectional and morphological SEM images for different types of spin-coated PIM deposits on ITO. The PIM film in Fig. 4a is formed from $1 \mathrm{wt} \%$ PIM in chloroform with an approximately $100-\mathrm{nm}$ thin film clearly visible (containing $\mathrm{PtCl}_{6}{ }^{2-}$ as "stain"). Films of vacuumcarbonised PIM (without Pt) also form well-defined films (Fig. 4b). However, when exploring cross-sectional images of 1 and 2 wt\% PIM films with $\mathrm{PtCl}_{6}{ }^{2-}$ immobilised, it is apparent that a part of the carbon deposit is missing (removed by the vacuum carbonisation process).

Additional morphological images (Fig. 4g, h) show that platinum is present (as nanostructured deposit on top of the ITO crystals), but evidence for the amount of the remaining cPIM substrate material is not clear. Next, XPS experiments were performed. Figure 5 shows survey data for PIM and PIM-Pt with the additional Pt signal clearly observed. After vacuum carbonisation of a thin film of PIM-EA-TB (from $1 \mathrm{wt} \%$ solution), cPIM (Fig. 5c) shows features identical to those reported recently [34]. The higher oxygen signals in cPIM compared to PIM are assigned to ingress and reactivity of oxygen after vacuum carbonisation when the sample is exposed to the open atmosphere. Nitrogen is present after carbonisation, but the level appears lower relative to that for carbon. For the Pt@cPIM film (Fig. 5d), significant changes occur and signals from ITO are clearly evident (compared to Fig. 5e). Carbon levels are higher compared to the bare ITO sample but lower when compared to the cPIM sample (Fig. 5c). Characteristic Pt4f peaks are observed (see insets) with a splitting into 7/2 and 5/2 states. Binding energies for Pt $4 \mathrm{f}$ in Fig. 5b are consistent with the $\mathrm{PtCl}_{6}^{2-}$ precursor [38] and in Fig. 5d with metallic platinum nanoparticles (see Table 1) [39].

It can be concluded that the vacuum carbonisation of thin film PIM is somewhat affected by the presence of $\mathrm{PtCl}_{6}{ }^{2-}$ (in part possibly due to the formation of volatile carbon halides) but that consistently, platinum metal in the form of nanoparticles is formed. Even for the thin film Pt@cPIM deposits, there remains carbon to act as substrate and conductive support for the catalyst. The electrocatalytic reactivity of these materials is investigated next.

\section{Electrocatalytic Oxygen Reduction}

Platinum catalysts are employed widely in fuel cells and particularly in the oxygen reduction reaction [40], which provides an enormous challenge for sustainable production. The reduction of oxygen is reported to be associated mainly with (i) reduction of $\mathrm{O}_{2}$ to a peroxide intermediate and (ii) further reduction to water (Eq. 1) [41].

$$
\begin{aligned}
& \mathrm{O}_{2}(\mathrm{aq})+2 \mathrm{H}^{+}(\mathrm{aq})+2 \mathrm{e}^{-}(\mathrm{m}) \rightarrow \mathrm{H}_{2} \mathrm{O}_{2}(\mathrm{ads}) \\
& \mathrm{H}_{2} \mathrm{O}_{2}(\mathrm{ads}) \leftrightarrow \mathrm{H}_{2} \mathrm{O}_{2}(\mathrm{aq}) \\
& \mathrm{H}_{2} \mathrm{O}_{2}(\mathrm{ads})+2 \mathrm{H}^{+}(\mathrm{aq})+2 \mathrm{e}^{-}(\mathrm{m}) \rightarrow 2 \mathrm{H}_{2} \mathrm{O}(\mathrm{aq})
\end{aligned}
$$

Recent work on PIM-EA-TB-stabilised platinum catalysts in oxygen reduction processes has been reported where the platinum nanoparticles and the carbon substrate were "protected" against accelerated corrosion [22]. Here, platinum nanoparticles are embedded into a hetero-carbon host with sufficient porosity to allow reagent access to the catalyst and with sufficient electrical conductivity to allow effective potential control. Figure 6a shows cyclic voltammetry data for "thick film" Pt@cPIM catalyst for the reduction of oxygen saturated in $0.1 \mathrm{M}$ phosphate buffer $\mathrm{pH} 7$ (trace iii). The reduction peak is detected at about $0.0 \mathrm{~V}$ versus SCE. When
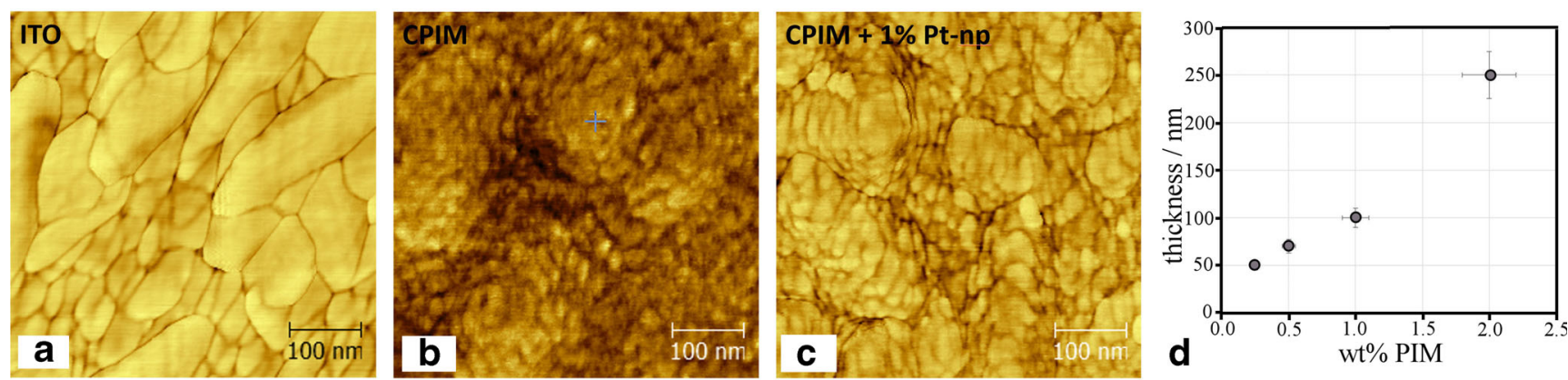

Fig. 3 Atomic force microscopy (AFM) images for a bare ITO, b cPIM-coated (1 wt $\%$ ) ITO and c Pt@cPIM (1 wt $\%)$ coated ITO. d Plot of crosssectional height data for $0.25,0.5,1$ and $2 \mathrm{wt} \%$ PIM-EA-TB in chloroform employed for spin coating 
Fig. 4 Cross-sectional scanning electron microscopy (SEM) images for a PIM-Pt (spin-coated from $1 \mathrm{wt} \%$ ), b cPIM showing the carbonised film without platinum, c Pt@cPIM (spin-coated from 1 wt\%) and d Pt@cPIM (spincoated from $2 \mathrm{wt} \%$ ). Loss of carbon material during carbonisation for the platinum containing films is evident. Also shown are SEM images for $\mathbf{e}$ base ITO, $\mathbf{f}$ cPIMcoated ITO,g Pt@cPIM (spincoated from $1 \mathrm{wt} \%)$ and $\mathbf{h}$ Pt@cPIM (spin-coated from $2 \mathrm{wt} \%)$
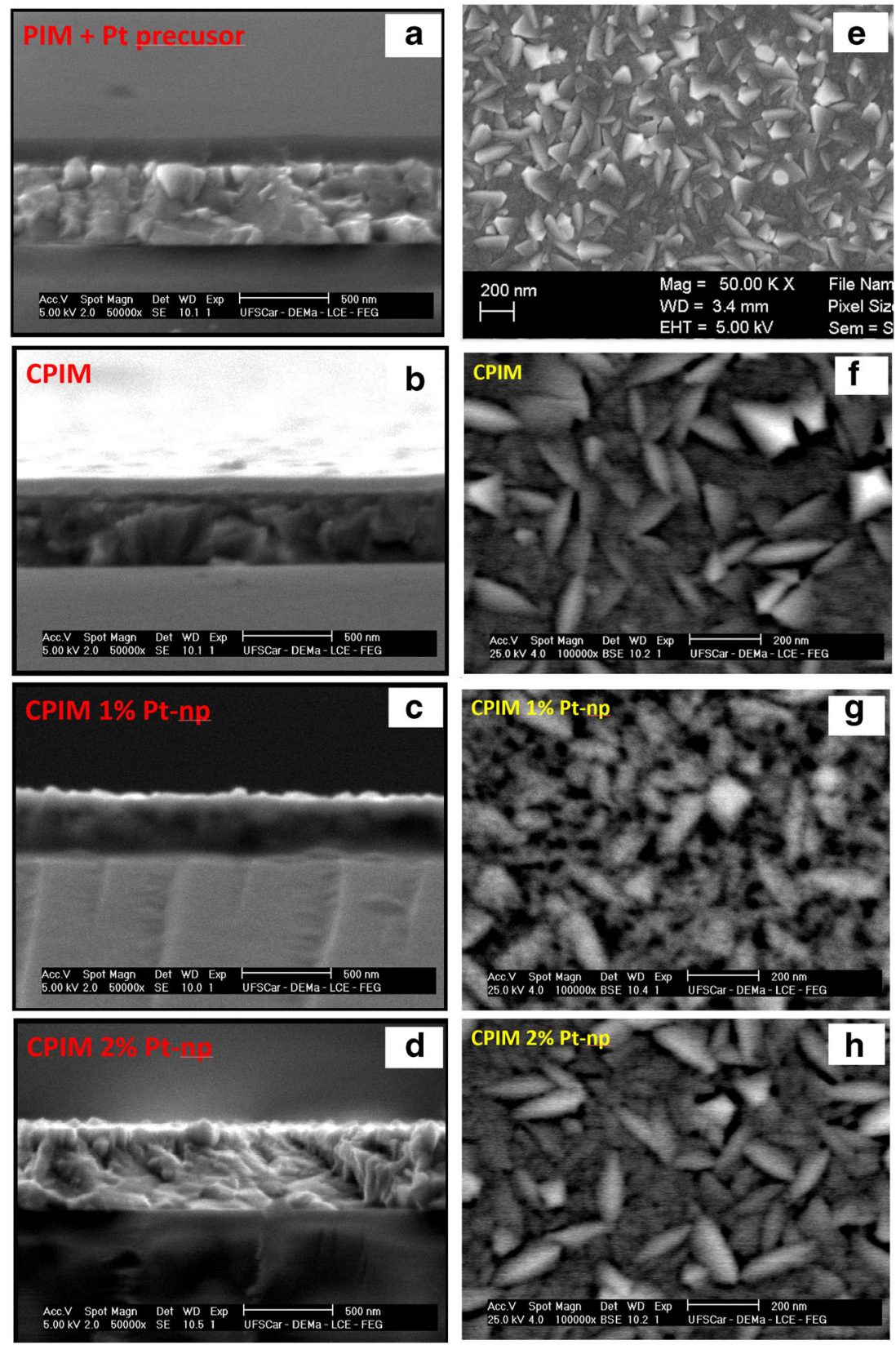

comparing with the reduction of $2 \mathrm{mM} \mathrm{H}_{2} \mathrm{O}_{2}$ in argondegassed solution, a similar reduction response is observed (trace ii) in addition to the voltammetric signal for the corresponding $\mathrm{H}_{2} \mathrm{O}_{2}$ oxidation. It seems likely that the reduction of oxygen under these conditions occurs predominantly with $\mathrm{H}_{2} \mathrm{O}$ as product (four-electron, see Eq. 1). Figure $6 \mathrm{~b}$ shows data for the corresponding processes at a 2-mm-diameter Pt disc electrode confirming the assigned mechanism.

Figure $6 \mathrm{c}$ shows cyclic voltammetry data obtained with "thin film”Pt@cPIM with increasing film thickness and platinum coverage values of (i) 0.9 , (ii) 1.3 , (iii) 2.3 and (iv) $5.4 \mu \mathrm{g} \mathrm{cm}^{-2}$
Pt. The surface area of platinum increases systematically with Pt@cPIM film thickness as seen from the hydrogen underpotential deposition (UPD) region (see Fig. 6c) and the oxide region. Similar experiments without PIM were performed by directly depositing $\mathrm{H}_{2} \mathrm{PtCl}_{6}$ platinum precursor onto ITO and thermal conversion without polymer (Fig. 6d). For this set of samples, surface area of platinum can be seen to remain well below that observed for Pt@ cPIM. Accordingly, the surface area and therefore the catalytic activity/utilisation of Pt@cPIM are improved due to the templating effect of the microporous polymer. Figure 6e shows data for the reduction of oxygen under 
Fig. 5 XPS survey spectra for a PIM-EA-TB, b PIM-EA-TB with Pt precursor absorbed, c carbonised PIM, $\mathbf{d}$ carbonised PIM-EA-TB with Pt precursor and $\mathbf{e}$ a bare ITO electrode substrate. Insets show Pt4f data for PIM-Pt and Pt@cPIM
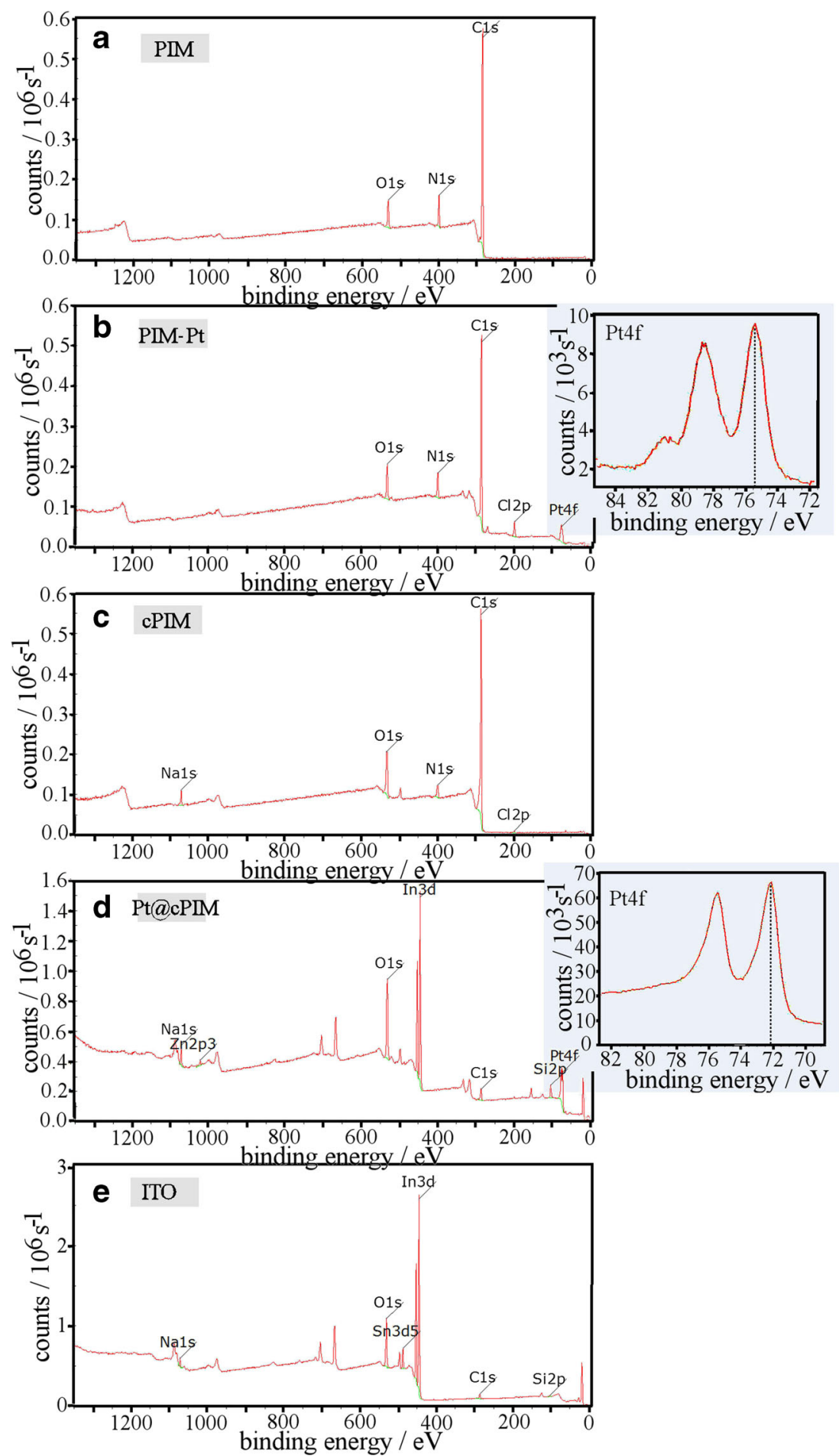

Table 1 Summary of XPS data for PIM-Pt and Pt@cPIM

\begin{tabular}{lcrrr}
\hline Element & $\begin{array}{l}\text { PIM-Pt } \\
\text { Peak (eV) }\end{array}$ & At\% & $\begin{array}{l}\text { Pt@cPIM } \\
\text { Peak (eV) }\end{array}$ & At\% \\
\hline $\mathrm{C} 1 \mathrm{~s}$ & $285.00^{\mathrm{a}}$ & 80.94 & $285.00^{\mathrm{a}}$ & 13.42 \\
$\mathrm{O} 1 \mathrm{~s}$ & 532.62 & 7.77 & 531.32 & 51.34 \\
$\mathrm{Pt4f}_{7 / 2}$ & 75.38 & 0.79 & 72.11 & 4.35 \\
\hline
\end{tabular}

${ }^{\mathrm{a}}$ The $\mathrm{C} 1 \mathrm{~s}$ binding energy was used as reference point with $285.00 \mathrm{eV}$ gentle hydrodynamic agitation (bubbling oxygen). The catalytic effect of approximately $2.3 \mu \mathrm{g}$ ( or ca. $1 \mu \mathrm{g} \mathrm{cm}^{-2}$ ) Pt in Pt@cPIM approaches that of bare platinum.

The ESA for platinum nanoparticles was estimated by cyclic voltammetry in $0.1 \mathrm{M} \mathrm{HClO}_{4}$ solution (saturated with argon). Figure $6 \mathrm{c}$ shows characteristic peaks for hydrogen adsorption $\left(\mathrm{H}_{\mathrm{ads}}\right)$ at -0.09 and $-0.17 \mathrm{~V}$ versus SCE. The 


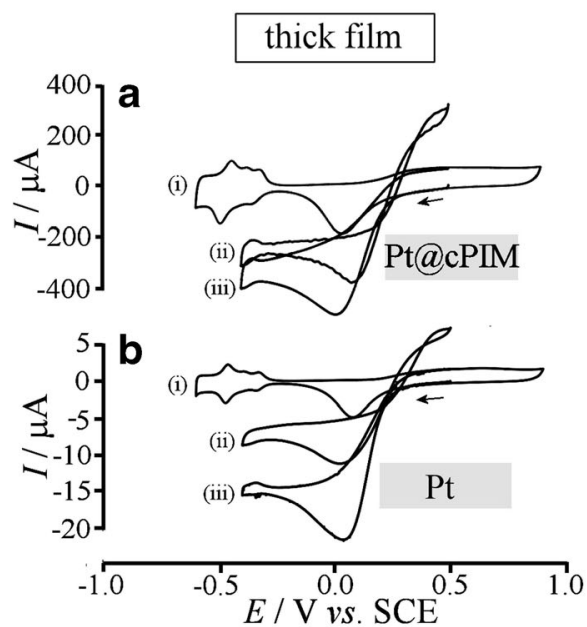

Fig. 6 a Cyclic voltammograms (scan rate $50 \mathrm{mV} \mathrm{s}^{-1}, 1-\mathrm{cm}^{2}$-thick Pt@cPIM) for argon-degassed solution (i), $2 \mathrm{mM} \mathrm{H}_{2} \mathrm{O}_{2}$ (ii) and oxygen saturated in $0.1 \mathrm{M}$ phosphate buffer pH 7 for thick film Pt@cPIM (iii). b As above for a 2-mm-diameter Pt disc electrode. c Cyclic voltammograms (scan rate $100 \mathrm{mV} \mathrm{s}{ }^{-1}, 2.2-\mathrm{cm}^{2}$-thin Pt@cPIM) for argondegassed $0.1 \mathrm{M} \mathrm{HClO}_{4}$ for 0.9 (i), 1.3 (ii), 2.3 (iii) and $5.4 \mu \mathrm{g} \mathrm{Pt}($ iv) and d pure Pt deposits for 9.7 (i), 39 (ii) and $97 \mu \mathrm{g} \mathrm{Pt} \mathrm{(iii).} \mathrm{e} \mathrm{Normalised}$ cyclic voltammograms for the reduction of oxygen in $0.1 \mathrm{M}$ perchloric acid for thin Pt@cPIM 0.9 (i), 1.3 (ii), 2.3 (iii) and $5.4 \mu \mathrm{g} \mathrm{Pt}$ (iv) and for pure Pt deposit $9.7 \mu \mathrm{g} \mathrm{Pt}(v)$. f Plot of electrochemically active surface area (ESA, estimated from HUPD region assuming $210 \mu \mathrm{C} \mathrm{cm}^{-2}$ [42]) versus platinum amount deposited
ESA value can be calculated by measurement of charge under the hydrogen electro-adsorption curve $\left(Q_{H}\right)$ using Eq. 2 [43].

$E S A=\frac{Q_{H}}{Q_{\text {ref }}}=\frac{Q_{H}}{210 \mu \mathrm{C} \mathrm{cm}^{-2}}$

Data are summarised in Fig. 6f. The ESA value for platinum nanoparticles supported on carbonised PIM is substantially higher compared to that for platinum produced without PIM. Data for ESA and for catalytic activity are also summarised in Table 2. Note that the ESA relative to the geometric surface area of the electrode reaches unity at about $1-2 \mu \mathrm{g} \mathrm{cm}^{-2}$. That is, a $1-2 \mu \mathrm{g} \mathrm{cm}^{-2}$ deposit offers a platinum surface similar to a bare platinum electrode.

\section{Electrocatalytic Methanol Oxidation}

Next, the reactivity of Pt@cPIM towards methanol oxidation was investigated. Small molecule $[44,45]$ and in particular methanol oxidation to $\mathrm{CO}_{2}$ (Eq. 3) have been extensively studied as a fuel cell process $[46,47]$. Platinum is commonly employed as catalyst component in methanol fuel cell devices [48].

$$
\begin{aligned}
& \mathrm{CH}_{3} \mathrm{OH}(\mathrm{aq}) \rightarrow \mathrm{CH}_{2} \mathrm{O}(\mathrm{aq})+2 \mathrm{H}^{+}(\mathrm{aq})+2 \mathrm{e}^{-}(\mathrm{m}) \\
& \mathrm{CH}_{2} \mathrm{O}(\mathrm{aq}) \rightarrow \mathrm{HCOOH}(\mathrm{aq})+2 \mathrm{H}^{+}(\mathrm{aq})+2 \mathrm{e}^{-}(\mathrm{m})
\end{aligned}
$$
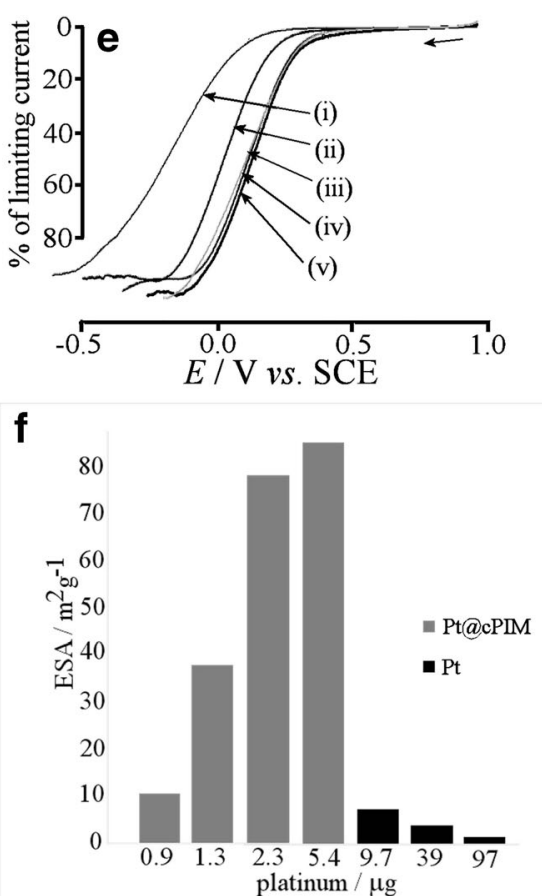

$\mathrm{HCOOH}(\mathrm{aq}) \rightarrow \mathrm{CO}_{2}(\mathrm{aq})+2 \mathrm{H}^{+}(\mathrm{aq})+2 \mathrm{e}^{-}(\mathrm{m})$

Figure 7a shows cyclic voltammetry data for the oxidation of $1 \mathrm{M}$ methanol in aqueous $0.1 \mathrm{M} \mathrm{HClO}_{4}$ at thin film Pt@cPIM catalyst with (i) 0.9 , (ii) 1.3 , (iv) 2.3 and (v) $5.4 \mu \mathrm{g}$ Pt (this refers to the calculated weight of platinum metal not the composite). For comparison, trace (iii) shows data for a $39 \mu \mathrm{g}$ Pt deposit without PIM support. Figure $7 \mathrm{~b}$ shows data for only platinum deposited from precursor onto ITO. The inset shows a plot correlating the peak current for methanol oxidation with the amount of Pt in Pt@cPIM. At substantially lower loading with Pt, the Pt@cPIM catalyst performs substantially better. Figure $7 \mathrm{e}$ compares catalytic current per gramme of platinum to give a measure of specific catalytic efficiency (mass activity based on the forward oxidation peak and the weight of platinum deposit). A loading of $2.3 \mu \mathrm{g}$ platinum appears to give the most effective methanol oxidation catalysts.

Additional experiments were performed to investigate the accelerated degradation of platinum catalyst under conditions of continuous potential cycling in aqueous $0.1 \mathrm{M} \mathrm{HClO}_{4}$ (Fig. 7c, d). Over 500 consecutive potential cycles, the Pt@cPIM catalyst performs better (ca. 30\% loss of Pt activity) compared to the directly deposited Pt (ca. 70\% loss of Pt activity). 
Table 2 Summary of film deposits in terms of specific electrochemical surface area (ESA), ESA relative to geometric surface area and methanol oxidation peak currents (see below)

\begin{tabular}{llllllll}
\hline Amount of Pt $(\mu \mathrm{g}$, on a $15 \times 15 \mathrm{~mm}$ ITO $)$ & 0.9 & 1.3 & 2.3 & 5.4 & 9.8 & 39 & 97.5 \\
\hline${\mathrm{ESA}\left(\mathrm{m}^{2} \mathrm{~g}^{-1}\right)}$ & 10.6 & 38.0 & 78.4 & 84.5 & 7.5 & 4.1 & 1.6 \\
$\mathrm{ESA}^{\mathrm{a}}\left(\mathrm{m}^{2} \mathrm{~m}^{-2}\right)$ & 0.04 & 0.23 & 0.83 & 2.07 & 0.32 & 0.71 & 0.67 \\
$I_{\text {peak }} \mathrm{b}(\mu \mathrm{A})$ & 85 & 249 & 1675 & 3827 & 665 & 1353 & 1352 \\
$i_{\text {peak }} \mathrm{b}\left(\mathrm{A} \mathrm{m}{ }^{-2}\right)$ & 0.38 & 1.11 & 7.44 & 17.0 & 2.96 & 6.01 & 6.01 \\
Specific catalytic current $\left(\mathrm{A} \mathrm{g}^{-1}\right)$ & 93 & 191 & 728 & 708 & 68 & 35 & 14 \\
\hline
\end{tabular}

${ }^{\text {a }}$ Area of platinum per geometric surface area of the electrode

${ }^{\mathrm{b}}$ Anodic peak current for $1 \mathrm{M}$ methanol in $0.1 \mathrm{M} \mathrm{HClO}_{4}$ during forward scan with $50 \mathrm{mV} \mathrm{s}^{-1}$ scan rate (see Fig. 7)

\section{Electrocatalytic Glucose Oxidation}

Glucose oxidation occurs on platinum electrode surfaces (mainly on catalytically active 100 oriented surfaces [49]) at relatively negative potentials within the hydrogen UPD region. The reaction mechanism is complex, but the main process has been suggested to be associated with a two-electron transformation from glucose to gluconic acid or gluconolactone [50] (Eq. 4).

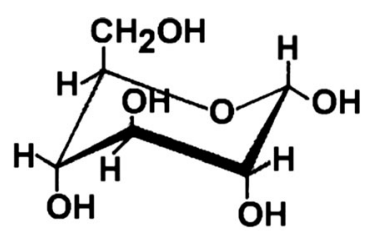

$\alpha$-D-glucose

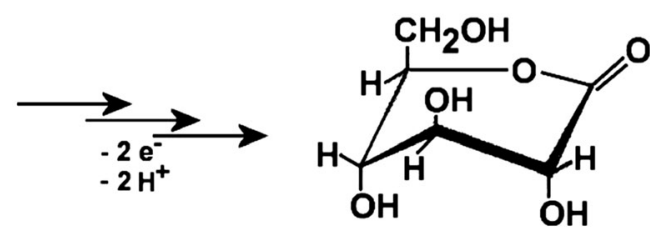

gluconolactone

(4)

Figure 8a shows cyclic voltammetry data for the oxidation of $10 \mathrm{mM}$ glucose in $0.1 \mathrm{M}$ phosphate buffer $\mathrm{pH} 7$ as a function of scan rate. A first oxidation peak is observed at $-0.4 \mathrm{~V}$ versus SCE consistent with literature reports [51]. This oxidation peak seems to originate from the $(111) \times(100)$ UPD region which, in turn, implies that hydrogen adsorption onto the platinum surface is an intermediate reaction step in the process described by Eq. 4. In Fig. 8b, data obtained at a bare 2-mm-diameter Pt disc electrode are shown and very similar features are observed. Figure $8 \mathrm{c}, \mathrm{d}$ reports the effect of changing the glucose concentration over a range from 2 to $14 \mathrm{mM}$ in $0.1 \mathrm{M}$ phosphate buffer $\mathrm{pH}$ 7. Well-defined peak currents are detected that correlate with glucose concentration up to approximately $10 \mathrm{mM}$. Beyond this point, the current becomes independent of the glucose concentration due to a lack of reactive surface sites. Both Pt@cPIM and bare platinum exhibit very similar trends when currents are normalised according to surface area (ESA). The difference in relative magnitude of the catalytic currents (ca. 1:100) at bare platinum and Pt@cPIM can be explained based on the ESA, which is ca. $4.3 \mathrm{~cm}^{2}$ for thick film Pt@cPIM compared to $0.04 \mathrm{~cm}^{2}$ for a 2 -mm-diameter platinum disc.
The oxidation of glucose on platinum is known to be very sensitive to poisons such as chloride $[52,53]$ and even phosphate. The effect of adding chloride is demonstrated in Fig. 9a, b for Pt@cPIM and for bare Pt, respectively. Both types of catalyst show substantial loss of activity in the presence of chloride. This needs to be taken into consideration in particular when using SCE reference electrodes, which tend to leak some chloride with time. In addition, phosphate buffer concentration affects the catalyst performance. Figure $9 \mathrm{c}, \mathrm{d}$ shows data for the oxidation of glucose in (i) 1.0 , (ii) 0.1 and (iii) $0.01 \mathrm{M}$ phosphate buffer $\mathrm{pH}$ 7. Both types of electrodes show similar trends with improved catalysis at lower phosphate buffer concentration.

Based on these data, it can be suggested that the microporous cPIM catalyst support for both thick film and thin film cases offers (i) sufficient electrical conductivity to allow catalysis at platinum nanoparticles, (ii) negligible surface blocking effects for embedded nanoparticles and (iii) sufficient porosity to allow oxygen, methanol, glucose and similar small molecules access to the embedded catalyst nanoparticles. 


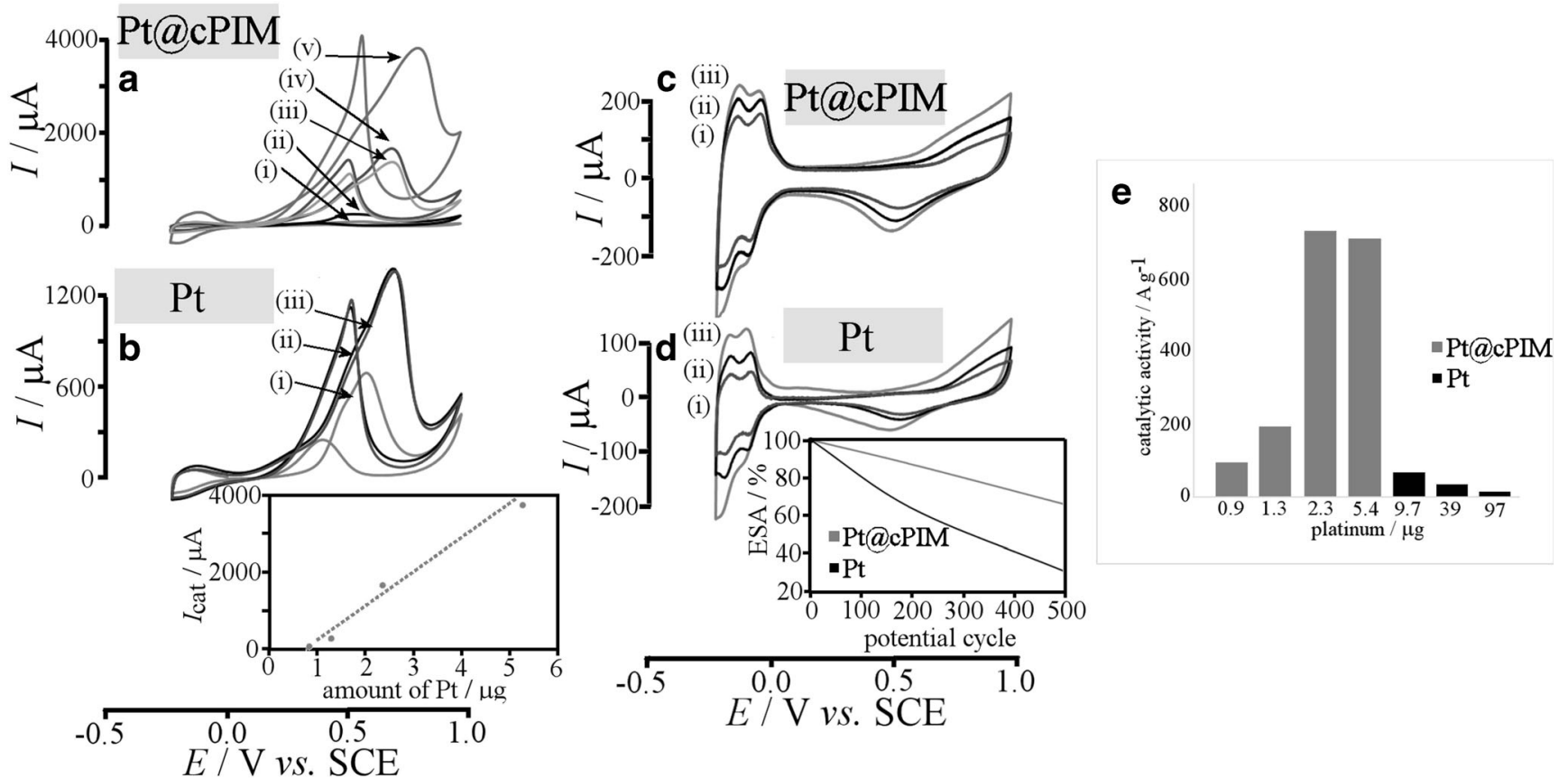

Fig. 7 Cyclic voltammograms (scan rate $50 \mathrm{mVs}^{-1}$ ) for the oxidation of $1 \mathrm{M}$ methanol in $0.1 \mathrm{M}$ perchloric acid a at thin film Pt@cPIM with 0.9 (i), 1.3 (ii), 2.3 (iv) and $5.4 \mu \mathrm{g} \mathrm{Pt}(v)$ and $39 \mu \mathrm{g}$ pure $\mathrm{Pt}$ (iii) and $\mathbf{b}$ at pure Pt deposits for 9.7 (i), 39 (ii) and $97 \mu \mathrm{g} \mathrm{Pt} \mathrm{(iii).} \mathrm{Inset} \mathrm{shows} \mathrm{catalytic}$ methanol oxidation current versus amount of Pt for thin film Pt@cPIM. c Accelerated degradation testing (multi-cycle voltammograms with scan

\section{Conclusion}

It has been demonstrated that PIM-EA-TB can be employed to immobilise a $\mathrm{PtCl}_{6}{ }^{2-}$ precursor for platinum by simple absorption from aqueous solution. Gentle vacuum carbonisation then rate of $50 \mathrm{mV} \mathrm{s}^{-1}$ ) performed in $0.1 \mathrm{M}$ perchloric acid for Pt@cPIM and $\mathbf{d}$ for pure Pt deposit. The inset shows the loss of active platinum surface area. e Plot of the specific mass activity (forward oxidation peak current divided by platinum weight) versus amount of Pt for different types of electrodes on ITO

allows platinum nanoparticle catalyst of typically 1.0 to 2.5 $\mathrm{nm}$ diameter to be formed. The substrate is converted to a microporous hetero-carbon with the ability to conduct electrons and without the problem of blockage of catalytic sites on platinum. Three types of relevant redox processes were

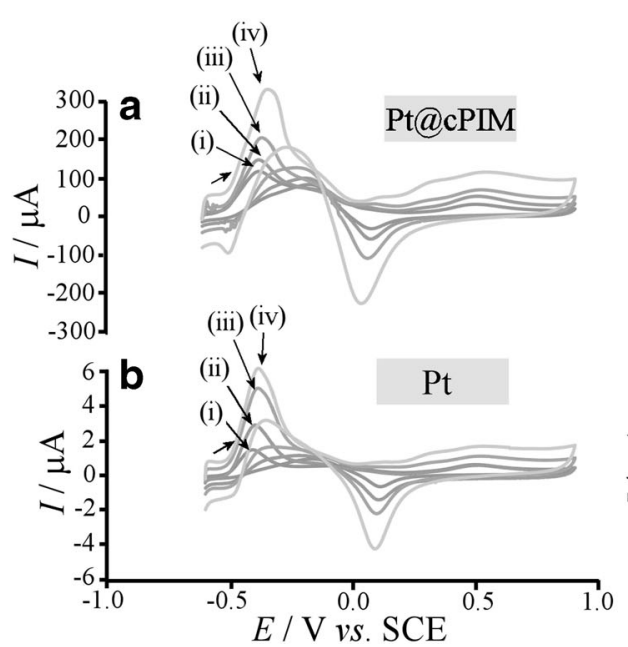

Fig. 8 Cyclic voltammograms (scan rate 5 (i), 10 (ii), 20 (iii), $50 \mathrm{mV} \mathrm{s}^{-1}$ (iv)) for the oxidation of $10 \mathrm{mM}$ glucose in $0.1 \mathrm{M}$ phosphate buffer $\mathrm{pH} 7 \mathbf{a}$ at a thick film Pt@cPIM electrode and b at a bare 2-mm-diameter Pt disc electrode. Next, cyclic voltammograms for the oxidation of 0 (i), 2 (ii), 4

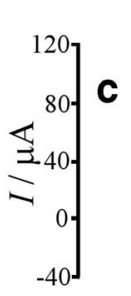

(iv) (vi) (vii)

(v) (viii)

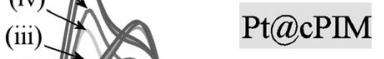

(ii) 12

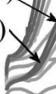

(vi) (vii)
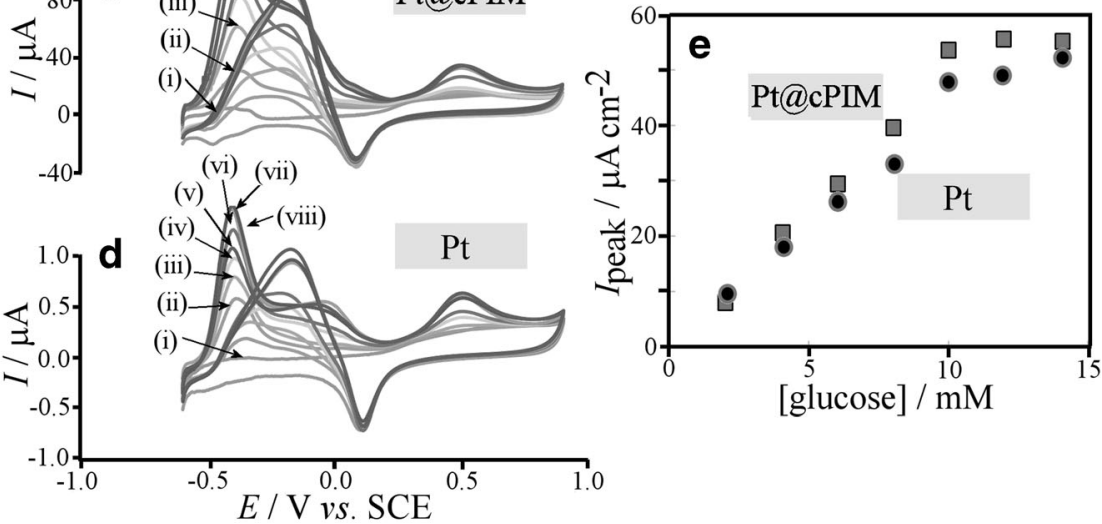

(iii), 6 (iv), 8 (v), 10 (vi), 12 (vii) and $14 \mathrm{mM}$ glucose (viii) in $0.1 \mathrm{M}$ phosphate buffer pH 7 at $\mathbf{c}$ thick film Pt@cPIM and d a bare 2-mmdiameter Pt disc electrode. e Plot of the normalised peak current density for glucose oxidation (based on ESA) versus glucose concentration 


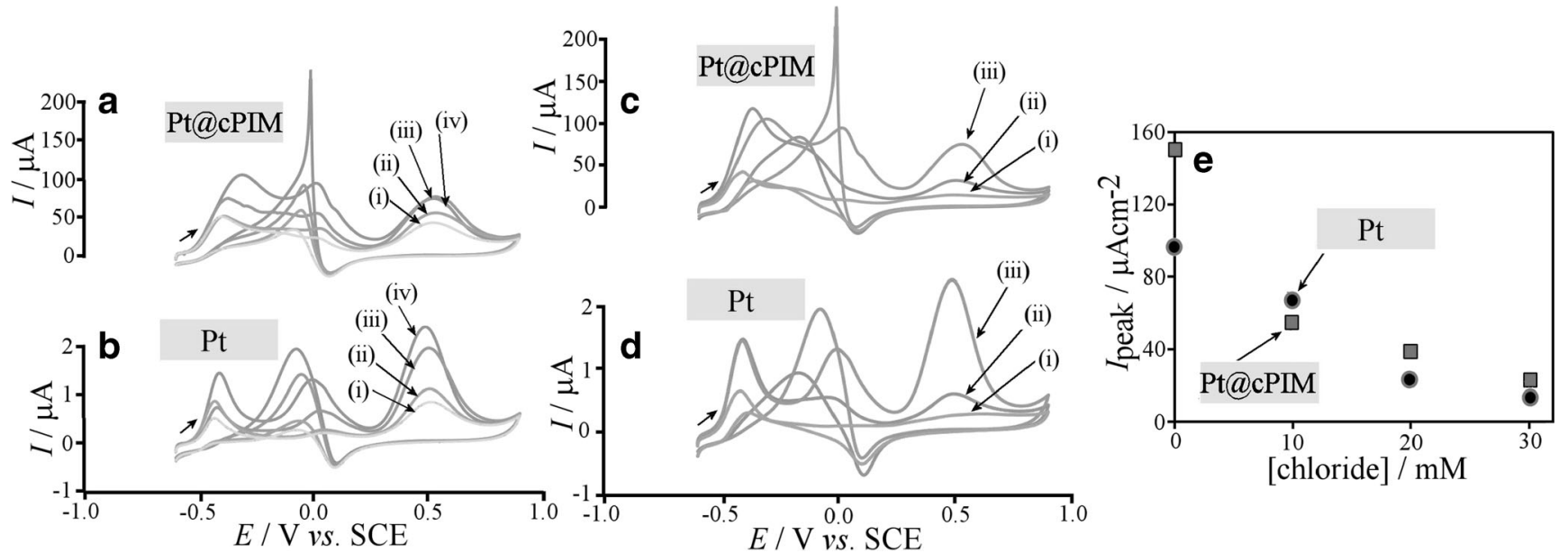

Fig. 9 Cyclic voltammograms (scan rate $50 \mathrm{mV} \mathrm{s}^{-1}$ ) for the oxidation of $10 \mathrm{mM}$ glucose in $0.1 \mathrm{M}$ phosphate buffer $\mathrm{pH} 7$ in the presence of $30(i)$, 20 (ii), 10 (iii), 0 mM chloride $(\mathrm{NaCl})($ iv) at a thick film Pt@cPIM and b bare 2-mm-diameter platinum. Next, cyclic voltammograms (scan rate $50 \mathrm{mV} \mathrm{s}^{-1}$ ) for the oxidation of $10 \mathrm{mM}$ glucose in aqueous $1.0 \mathrm{M}(i)$,

investigated: (i) the reduction of oxygen, (ii) the oxidation of methanol and (iii) the oxidation of glucose. For each case, good performance of the Pt@cPIM nanocatalyst is observed. A coverage of typically $1 \mu \mathrm{g} \mathrm{cm}{ }^{-2}$ of Pt provided by Pt@cPIM appears to be as catalytically reactivity as bare platinum. This estimate can be compared to the geometric area calculated for an amount of platinum of $\sim 1 \mathrm{\mu g} \mathrm{cm}^{-2}$ in the form of platinum nanoparticles of 2-nm diameter. This would indeed result in approximately $1-\mathrm{cm}^{2}$ geometric surface area. Therefore, Pt@cPIM appears to provide maximum utilisation with all particles accessible and active in the molecularly rigid host material. At this stage, many experimental parameters remain unexplored and further study of platinum loading, carbonisation conditions and the effects introduced by different types of PIMs will be necessary. Powder samples will have to be prepared and applied as inks in order to allow more quantitative comparison to commercial standard catalysts.

We anticipate that the vacuum carbonisation of PIMs with a range of different catalyst precursors will provide a general methodology for the production of high-performance catalysts for various applications in electrochemistry. Instead of directly coating electrodes with films of PIM precursors, it will be beneficial to prepare bulk catalyst materials, which are then employed as an ink to apply to suitable electrode surfaces. The rigidity in the molecular backbone of PIMs ensures minimal loss of catalyst surface activity, whilst high temperature carbonisation allows the metal catalyst to form and restructure the matrix to an electrically conducting but still microporous substrate. Further work is planned to explore other types of reactions and applications.

Acknowledgements Y.R. thanks the University of Bath for a fee waiver and the China Scholarship Council for a Ph.D. stipend. D.H. thanks the Royal Society for a Newton International Fellowship. F.M. and N.B.M.
$0.1 \mathrm{M}$ (ii) and $0.01 \mathrm{M}$ (iii) phosphate buffer pH 7 at c thick film Pt@ cPIM and $\mathbf{d}$ bare 2-mm-diameter platinum disc. e Plot of the catalytic glucose oxidation current peak density (based on ESA) versus chloride concentration

thank the Leverhulme Foundation for financial support (RPG-2014-308: "New Materials for Ionic Diodes and Ionic Photodiodes").

Open Access This article is distributed under the terms of the Creative Commons Attribution 4.0 International License (http:// creativecommons.org/licenses/by/4.0/), which permits unrestricted use, distribution, and reproduction in any medium, provided you give appropriate credit to the original author(s) and the source, provide a link to the Creative Commons license, and indicate if changes were made.

\section{References}

1. H. Mistry, A.S. Varela, S. Kuhl, P. Strasser, B.R. Cuenya, Nat. Rev. Mater. 1, 16009 (2016)

2. M. Zhou, S.J. Guo, Chem. Cat. Chem. 7, 2744 (2015)

3. Y. Xu, B. Zhang, Chem. Soc. Rev. 43, 2439 (2014)

4. S. Sharma, B.G. Pollet, J. Power Sources 208, 96 (2012)

5. J. Biener, M. Stadermann, M. Suss, M.A. Worsley, M.M. Biener, K.A. Rose, T.F. Baumann, Energy Environm. Sci. 4, 656 (2011)

6. W. Xia, A. Mahmood, R.Q. Zou, Q. Xu, Energy Environm. Sci. 8, $1837(2015)$

7. L. Liu, Y.P. Zhu, M. Su, Z.Y. Yuan, Chem Cat Chem 7, 2765 (2015)

8. C.R. Kim, T. Uemura, S. Kitagawa, Chem. Soc. Rev. 45, 3828 (2016)

9. Q. Li, N. Mahmood, J.H. Zhu, Y.L. Hou, S.H. Sun, Nano Today 9 , 668 (2014)

10. P. Xu, X.J. Han, B. Zhang, Y.C. Du, H.L. Wang, Chem. Soc. Rev. 43, 1349 (2014)

11. H.L. Fan, W.Z. Shen, Chem SusChem 8, 2004 (2015)

12. Z.L. Xie, D.S. Su, Europ. J. Inorg. Chem. 1137 (2015)

13. J. Yin, L. Wang, P. Yu, L. Zhao, C.G. Tian, B.J. Jiang, D.D. Zhao, W. Zhou, H.G. Fu, Chem Electro Chem 2, 1813 (2015)

14. Y.Q. Cao, J.W. Zhang, Y. Yang, Z.R. Huang, N.V. Long, M. Nogami, J. Nanosci. Nanotechnol. 14, 1194 (2014)

15. L. Su, W.Z. Jia, C.M. Li, Y. Lei, Chem SusChem 7, 361 (2014)

16. R.N. Singh, R. Awasthi, C.S. Sharma, Internat. J. Electrochem. Sci. 9, 5607 (2014)

17. A. Brouzgou, P. Tsiakaras, Topics Catal. 58, 1311 (2015)

18. M.X. Wu, T.L. Ma, J. Phys. Chem. C 118, 16727 (2014) 
19. S. Marini, P. Salvi, P. Nelli, R. Pesenti, M. Villa, M. Berrettoni, G. Zangari, Y. Kiros, Electrochim. Acta 82, 384 (2012)

20. E. Antolini, Appl. Catal. B-Environm. 181, 298 (2016)

21. L. Li, L.P. Hu, J. Li, Z.D. Wei, Nano Res. 8, 418 (2015)

22. D.P. He, Y.Y. Rong, Z.K. Kou, S.C. Mu, T. Peng, R. MalpassEvans, M. Carta, N.B. McKeown, F. Marken, Electrochem. Commun. 59, 72 (2015)

23. D.P. He, Y.Y. Rong, M. Carta, R. Malpass-Evans, N.B. McKeown, F. Marken, RSC Adv. 6, 9315 (2016)

24. W. Xia, A. Mahmood, Z.B. Liang, R.Q. Zou, S.J. Guo, Angew. Chem. Int. Ed. 55, 2650 (2016)

25. A. Afraz, A.A. Rafati, A. Hajian, M. Khoshnood, Electrocatalysis 6, $220(2015)$

26. T. Xue, Z.P. Sun, L. Wei, X. Wang, J.M. Lee, Int. J. Hydrog. Energy 38, 2754 (2013)

27. Y.Y. Rong, D.P. He, A. Sanchez-Fernandez, C. Evans, K.J. Edler, R. Malpass-Evans, M. Carta, N.B. McKeown, T.J. Clarke, S.H. Taylor, A.J. Wain, J.M. Mitchels, F. Marken, Langmuir 31, 12300 (2015)

28. N.B. McKeown, P.M. Budd, Chem. Soc. Rev. 35, 675 (2006)

29. N.B. McKeown, P.M. Budd, Macromolecules 43, 5163 (2010)

30. N.B. McKeown, P.M. Budd, K.J. Msayib, B.S. Ghanem, H.J. Kingston, C.E. Tattershall, S. Makhseed, K.J. Reynolds, D. Fritsch, Chem. European J. 11, 2610 (2005)

31. S. Kim, Y.M. Lee, Prog. Polymer Sci. 43, 1 (2015)

32. Y.Y. Rong, R. Malpass-Evans, M. Carta, N.B. McKeown, G.A. Attard, F. Marken, Electrochem. Commun. 46, 26 (2014)

33. E. Madrid, Y.Y. Rong, M. Carta, N.B. McKeown, R. MalpassEvans, G.A. Attard, T.J. Clarke, S.H. Taylor, Y.T. Long, F. Marken, Angew. Chem. Int. Ed. 53, 10751 (2014)

34. Y.Y. Rong, R. Malpass-Evans, M. Carta, N.B. McKeown, G.A. Attard, F. Marken, Electroanalysis 26, 904 (2014)

35. M. Carta, R. Malpass-Evans, M. Croad, Y. Rogan, J.C. Jansen, P. Bernardo, F. Bazzarelli, N.B. McKeown, Science 339, 303 (2013)
36. Y. Rogan, R. Malpass-Evans, M. Carta, M. Lee, J.C. Jansen, P. Bernardo, G. Clarizia, E. Tocci, K. Friess, M. Lancd, N.B. McKeown, J. Mater. Chem. A 2, 4874 (2014)

37. J.P. Xie, Q.B. Zhang, W.J. Zhou, J.Y. Lee, D.I.C. Wang, Langmuir 25, 6454 (2009)

38. A. Drelinkiewicz, J.W. Sobczak, E. Sobczak, M. Krawczyk, A. Zieba, A. Waksmundzka-Gora, Mater. Chem. Phys. 114, 763 (2009)

39. J.M. Kinyanjui, R. Harris-Burr, J.G. Wagner, N.R. Wijeratne, D.W. Hatchett, Macromolecules 37, 8745 (2004)

40. M.H. Shao, Q.W. Chang, J.P. Dodelet, R. Chenitz, Chem. Rev. 116, 3594 (2016)

41. V. Stamenkovic, N.M. Markovic, P.N. Ross, J. Electroanal. Chem. 500, 44 (2001)

42. T. Biegler, D.A.J. Rand, R. Woods, J. Electroanalytical Chem. 29 269 (1971)

43. C.E. Hotchen, G.A. Attard, S.D. Bull, F. Marken, Electrochim. Acta 137, 484 (2014)

44. J. Jiang, A. Kucernak, J. Electroanal. Chem. 543, 187 (2003)

45. J. Jiang, A. Kucernak, J. Electroanal. Chem. 533, 153 (2002)

46. J.N. Tiwari, R.N. Tiwari, G. Singh, K.S. Kim, Nano Energy 2, 553 (2013)

47. D.S. Falcao, V.B. Oliveira, C.M. Rangel, A.M.F.R. Pinto, Renew. Sust. Energy Rev. 34, 58 (2014)

48. Y.W. Lee, S. Cha, K.W. Park, J.I. Sohn, J. Kim, J. Nanomater. 273720 (2015)

49. A. Rodes, M.J. Llorca, J.M. Feliu, J. Clavilier, Anales Quimica 92, 118 (1996)

50. S. Park, H. Boo, T.D. Chung, Anal. Chim. Acta 556, 46 (2006)

51. Y. Holade, C. Morais, K. Servat, T.W. Napporn, K.B. Kokoh, Phys. Chem. Chem. Phys. 16, 25609 (2014)

52. N. Job, M. Chatenet, S. Berthon-Fabry, S. Hermans, F. Maillard, J. Power Sources 240, 294 (2013)

53. J. Weber, A.J. Wain, G.A. Attard, F. Marken, Electroanalysis (2016). doi:10.1002/elan.201600443 